\title{
Development and Validity Assessment of a Chronic Obstructive Pulmonary Disease Knowledge Questionnaire in Low- and Middle-Income Countries
}

Nicole M Robertson MPH ${ }^{1,2}$, Trishul Siddharthan MD ${ }^{1,2}$, Suzanne L Pollard PhD ${ }^{1,2}$, Patricia Alupo $\mathrm{MBChB}^{3}$, MMed, Oscar Flores-Flores MD, MSc ${ }^{2,4,5,6}$, Natalie A Rykiel $\mathrm{MSc}^{1,2}$, Elisa D Romani RN,Msc ${ }^{2,4}$, Ivonne Ascencio-Días RN, MPH ${ }^{4}$, Bruce Kirenga MBChB, MMed ${ }^{3,7}$, William Checkley MD, PhD ${ }^{1,2}$, John R Hurst PhD, FRCP ${ }^{8}$, Shumonta Quaderi MRCP, MBBS ${ }^{8}$; GECo Investigators

1. Division of Pulmonary and Critical Care, School of Medicine, Johns Hopkins University, Baltimore, USA

2. Center for Global Non-Communicable Disease Research and Training, Johns Hopkins University, Baltimore USA

3. Department of Medicine and Lung Institute, College of Health Sciences, Makerere University, Kampala, Uganda.

4. Biomedical Research Unit, A.B. PRISMA, Lima, Peru.

5. Universidad de San Martin de Porres, Facultad de Medicina Humana, Centro de Investigación del Envejecimiento (CIEN), Lima, Peru.

6. Universidad Cientifica de Sur, Facultad de Ciencias de la Salud, Lima, Peru

7. Department of Physiology, College of Health Sciences, Makerere University, Kampala, Uganda

8. UCL Respiratory, University College London, London, UK

Running Title: COPD Knowledge Questionnaire

Descriptor Number: 2.03 Health Education/Disease Prevention/Patient Education Keywords: COPD, questionnaires, patient education

Funding: This research was funded by the Medical Research Council Grant MR/P008984/1 under the Global Alliance for Chronic Disease, an Etscorn Summer International Research Award, and OFF was supported by NIH Research Training Grant \# D43 TW009340 funded by the NIH Fogarty International Center, NINDS, NIMH, and NHBLI.

ICJME Statement: Concept and Design: NMR, TS, SP, SQ; Analysis and interpretation: NMR, TS, SP; Drafting manuscript for important intellectual content:

NMR, TS, SP, SQ; Revising Manuscript for important intellectual content: NMR, TS, SP, PA, OF, NAR, ER, IA, BK, WC, JRH, SQ;

Word count: 3400

\section{Correspondence:}

Nicole Robertson

800 Rose Street, University of Kentucky College of Medicine, Lexington, KY 40506

Email: nicole.robertson@uky.edu 


\begin{abstract}
Rationale: The majority of the morbidity and mortality related to chronic obstructive pulmonary disease (COPD) occurs in low- and middle-income countries (LMICs). Despite the increasing burden of COPD, disease-specific knowledge among healthcare workers (HCWs) and patients in LMICs remains limited. COPD knowledge questionnaires are valid and reliable tools to assess COPD knowledge and can be employed in settings with limited health literacy.
\end{abstract}

Objective: To develop and assess validity and reliability of a COPD knowledge questionnaire among individuals with COPD in three LMIC settings.

Methods: Twelve questions were generated by an expert team of sixteen researchers, physicians, and public health professionals to create an LMIC-specific COPD knowledge questionnaire. Content was based on previous instruments, clinical guidelines, focus group discussions, and questionnaire piloting. Participants with COPD completed the questionnaire across three diverse LMIC settings before and three months after delivery of a standardized COPD specific education package by a local community health worker (CHW) trained to deliver the education to an appropriate standard. We utilized paired t-tests to assess improvement in knowledge postintervention.

Results: Questionnaire development initially yielded 52 items. Based on community feedback and expertise, items were eliminated and added yielding a final 12-item questionnaire, with a maximum total score of 12 . A total of 196 participants with COPD were included this study in Nepal $(n=86)$, Peru $(n=35)$ and Uganda $(n=75)$. Mean $( \pm$ SD) baseline score was $8.0 \pm 2.5$ and 3-months post-education the mean score was $10.2 \pm$ 1.7 among participants. The CHW-led COPD educational intervention improved COPD knowledge among community members by 2.2 points $(95 \% \mathrm{Cl} 1.8$ to $2.6, \mathrm{t}=10.9$, $\mathrm{p}<0.001)$. Internal consistency using Cronbach's alpha was 0.75 .

Conclusion: The LMIC COPD-KQ demonstrates face and content validity and acceptable internal consistency through development phases, suggesting a reliable and valid COPD education instrument that can be utilized to assess educational interventions across LMIC settings.

Primary Source of Funding: Funded by Medical Research Council Grant MR/P008984/1 under the Global Alliance for Chronic Disease, Etscorn Summer International Research Award, and OFF was supported by NIH Research Training Grant \# D43 TW009340 funded by the NIH Fogarty International Center, NINDS, NIMH, and NHBLI. 


\section{INTRODUCTION}

Chronic obstructive pulmonary disease (COPD) is the third leading cause of death worldwide with over $90 \%$ of COPD-related deaths occurring in low- and middle-income countries (LMICs). ${ }^{1}$ COPD is a long-term lung disease that affects people exposed to sufficient environmental stimulus, such as exposure to biomass fuels and tobacco smoke. ${ }^{2}$ The global burden of COPD is expected to increase over the next decade, with LMICs expected to have the largest burden of disease. ${ }^{3}$

Chronic management of COPD is complex and based on disease-specific knowledge including risk factors, symptoms, and exacerbations. To effectively treat and manage their disease, it is important that COPD patients gain knowledge about COPD and develop the self-efficacy, or the agency to implement COPD knowledge and skills into their own self-management. Patients should develop an understanding about the disease progression, purposes and types of treatments, methods to management acute episodes, and how to management environmental exposures. ${ }^{4,5}$ Self-management has been described as formalized patient education programs that teach skills and provide support for health-promoting behavior. ${ }^{6}$ In LMICs COPD disease-management interventions have included health education sessions, one-on-one counseling, print materials, and in-patient self-management sessions. ${ }^{7}$ These COPD diseasemanagement programs focusing on patient education have been demonstrated to improve COPD-related knowledge, health-related quality of life and health-related outcomes, but further research is needed in LMICs. ${ }^{8-11}$ 
Given the current and rising global burden of COPD, there is an increasing focus on the delivery and evaluation of educational interventions, especially in LMICs. ${ }^{10}$ The aim of this study was to develop and assess the validity and reliability of a COPD knowledge questionnaire to test the effectiveness of an education intervention, for use in adult COPD patients in LMIC settings. Some of the results of these studies have been previously reported in the form of an abstract. ${ }^{12}$

\section{METHODS}

\section{Study setting}

This study was carried out in three diverse LMIC settings in Bhaktapur, Nepal; Lima, Peru; and Nakaseke, Uganda. ${ }^{13} \mathrm{Nepal}$ is a low-income country located in Southeast Asia with a total population of 26.5 million, and Bhaktapur, our research site, is located 8 miles east of the capital city of Kathmandu. Peru is an upper-middle-income country located in South America with a population of 30.5 million, of which $78.6 \%$ is urban. We conducted our study at Pampas de San Juan de Miraflores, a peri-urban community in southern Lima, Peru's capital. Uganda is a low-income country located in East Africa with a total population of 42 million. Our study site, Nakaseke, is characterized as a rural, under-resourced district in Central Uganda.

\section{Study design}

We conducted this study among adults with COPD identified as part of the ongoing Global Excellence in COPD Outcomes (GECo) self-management trial. ${ }^{13}$ Participants were individuals over 40 years who resided in Bhaktapur, Nepal; Lima, Peru; and 
Nakaseke, Uganda; and were diagnosed with COPD using quality-assured spirometry. All participants were already enrolled participants as a part of the larger GECo study. ${ }^{13}$ Data were collected from January 2018 - June 2020 by trained research assistants using RedCAP. ${ }^{14}$ We describe four phases in the development and evaluation of the COPD-KQ: (1) Questionnaire development and item generation, (2) Selection of expert reviewers and initial questionnaire development, (3) Quality assessment and field testing for comprehension of items, and (4) Evaluation of changes in knowledge before and after educational intervention as outlined in Figure 1.

\section{Questionnaire development and item generation}

We conducted qualitative interviews with healthcare providers, community health workers (CHWs), and community members diagnosed with COPD to conceptualize experiences surrounding COPD and inform item development. ${ }^{15,16}$ Semi-structured interviews identified common beliefs and COPD illness representation in the Bhaktapur, Lima, and Nakaseke communities. Interviews explored awareness of COPD, causes, symptoms, diagnosis, management, and treatment of COPD, and interactions between healthcare providers, $\mathrm{CHWs}$ and COPD patients. This qualitative data informed the initial questionnaire items during development.

\section{Selection of expert reviewers and initial questionnaire development}

A multidisciplinary expert panel of 16 respiratory clinicians, researchers, and public health professionals from Nepal, Peru, Uganda, UK, and US discussed the domains to be assessed by the instrument. The expert panel collectively established its aim to 
assess COPD causes, symptoms of COPD, exacerbation behaviors, and COPD treatment. To develop the COPD knowledge questionnaire content, a scoping literature review was performed, reviewing current knowledge assessments for COPD and other non-communicable diseases such as asthma, diabetes, and cystic fibrosis. ${ }^{10,}{ }^{17-20}$ Items were based on qualitative research findings, expert panel's expertise, and COPD management guidelines. ${ }^{2}$ Questionnaire development initially yielded 52 -items. The item response categories were determined to be "True," "False," or "I don't know" to increase reliability of the instrument by reducing guessing between true or false options only. ${ }^{21}$ The questions were translated from English to the local languages - Nepali, Spanish and Luganda respectively - by translators who were familiar with COPD and medical terminology.

\section{Qualitative assessment and field testing for comprehension of items}

We first carried out seven focus group discussions with local field team members (outside of the expert panel members) and CHWs with leadership roles (three in Uganda and four in Peru). Each questionnaire item was discussed to achieve lay understanding and clarity as intended by the research team. Subsequently, the questionnaire was piloted with a new group of CHWs (42 in Uganda, 14 in Peru, and 19 in Nepal) at a COPD education training session carried out by our research team of local physicians and research staff. Following the pilot, local physicians and research staff from the research team solicited written and oral feedback regarding the clarity and content of questions. Questionnaires were scored to evaluate the score distributions and initial performance. Questionnaire items with the lowest accuracy during piloting 
were eliminated. Based on this feedback, we rephrased, eliminated, and added questions through discussions with the expert panel.

Based on community feedback, aims, and expertise in the expert panel members' respective fields, items were further eliminated and added yielding a final 12 -item questionnaire (Table 1). The wording of items was reviewed and altered by each panel member upon group agreement. The COPD questionnaire instructions, layout, and individual items were revised to incorporate expert panel member's feedback. The final translations of the resulting LMIC COPD Knowledge Questionnaires (LMIC COPD-KQ) were then reviewed by teams of local clinicians, field staff, and study investigators at each of the sites in order to review for syntax and grammar in the language of each study site. The questionnaire was standardized among the three study sites to be applicable to LMIC settings. Input from the 16-person expert panel and feedback from CHW focus group discussions yielded a final 12-item questionnaire (Table 1). A combination of expert opinion and community input likely led to strong content and face validity covering a satisfactory overview of COPD concepts.

\section{Evaluation of changes in knowledge before and after educational intervention}

We delivered and trained CHWs in standardized COPD education. We performed fidelity checks for each $\mathrm{CHW}$ during education delivery to ensure high standards were upheld. After obtaining informed consent, research assistants orally administered the LMIC COPD-KQ to GECo study participants to gauge baseline knowledge (before intervention) surrounding COPD, at recruitment to the trial. To our knowledge, 
participants had no prior COPD education or formal education in chronic respiratory disease risk factors, treatment, and management. $\mathrm{CHWs}$ then delivered COPD-specific education to GECo participants across the three sites concerning pathophysiology, common treatments and guidelines for the diagnosis, prevention, management, and treatment of COPD using flipcharts. ${ }^{13}$ Each training was approximately 30-60 minutes and consisted of an additional self-management action plan and 12 months of $\mathrm{CHW}$ educational visits for those in the intervention group. After education, at three-month follow up, the LMIC COPD-KQ was administered again to the participants. Participants were given as much time as requested to complete questionnaires to prevent bias from time constraints and forced choice. ${ }^{22}$

Ethics approval was granted by the University College London Research Ethics Committee (9661/001) in London, UK, School of Medicine of Johns Hopkins University (IRB00139901) in Baltimore, USA, the Nepal Health Research Council (136/2017) in Kathmandu, Nepal, A.B. PRISMA (CE2147.17) in Lima, Peru, Uganda National Council for Science and Technology, and Makerere School of Medicine (SOMREC 2017-096) in Kampala, Uganda.

\section{Statistical analysis}

Our analysis aimed to evaluate participant demographics, participant questionnaire performance, questionnaire internal consistency, and questionnaire item performance. A score of 1 was given to a correct answer and a score of 0 was given to an incorrect, missing, or "I don't know" answer. Therefore, questionnaire performance was scored 
based on the number correct responses. A minimum of over $80 \%$ (10 questions) questionnaire completion was required for response to be included in the data analysis Participant COPD-KQ scores were evaluated for distribution and outliers. To assess questionnaire performance, the paired t-test was used to compare the total score baseline and 3-months after education between groups. To evaluate coefficient reliability, Cronbach's alpha was used to measure the internal consistency of individual LMIC COPD-KQ items. Data were analyzed using IBM Statistical Package for the Social Sciences (SPSS 26.0, Armonk, NY: IBM Corp).

\section{RESULTS}

\section{Demographic Characteristics of Participants}

The demographic characteristics of participants are reported in Table 2. 196 participants were from Nepal $(n=86)$, Peru $(n=35)$, and Uganda $(n=75)$. The mean age was 67.4 years (SD 9.4). $58.7 \%(n=115)$ of participants were male.

\section{COPD Knowledge Questionnaire Performance}

No participants had more than two missing responses on an administered questionnaire, so none were excluded from analyses. Among all three sites, the mean test score at baseline was 8.0 (SD 2.5) and 3-months after education the mean test score was 10.2 (SD 1.7). The CHW COPD education intervention improved COPD knowledge among community members $(t=10.9, p<0.001)$. The intervention improved score, on average, by 2.20 points $(95 \% \mathrm{Cl} 1.8$ to 2.6$)$. At baseline $29.6 \%(n=58)$ participants scored over $80 \%$ (10 or more questions) accuracy on the COPD-KQ, and 
post-education $67.3 \%(n=132)$ participants scored over $80 \%$ (10 or more questions) accuracy, which was not a statistically significant increase $(p=0.189)$. The proportion of participants that scored over $80 \%$ (10 or more questions) accuracy on the COPD-KQ at baseline and post-education increased at all three sites-Nepal (44.2\% vs. $65.1 \%)$, Peru (28.6\% vs. $62.9 \%)$, and Uganda (13.3\% vs. $72.0 \%)$.

In Peru, the mean test score at baseline was 7.0 (SD 3.3) and 3-months after education the mean test score was 9.8 (SD 1.6). Among Peruvian participants, the CHW COPD education intervention improved COPD knowledge by 2.7 points $(95 \% \mathrm{Cl} 1.7$ to 3.8$)(\mathrm{t}=$ 5.4, $\mathrm{p}<0.001$ ). In Nepal, the mean test score at baseline was 8.9 (SD 2.0) and 3-months post-education the mean test score was 10.1 (SD 1.8). For Nepali participants the CHW COPD education intervention improved COPD knowledge by 1.1 points $(95 \% \mathrm{Cl} 0.6$ to 1.7) $(\mathrm{t}=4.4, \mathrm{p}<0.001)$. In Uganda, the mean test score at baseline was 7.3 (SD 2.2) and 3-months after education the mean test score was 10.5 (SD 1.5). Ugandan participants had the greatest improvement in COPD knowledge scores between baseline and posteducation of 3.2 points $(95 \% \mathrm{Cl} 2.5$ to 3.8$)(t=9.8, p<0.001$.

Internal consistency of the COPD knowledge questionnaire using Cronbach's alpha, was 0.75 , which is acceptable internal consistency. Acceptably high values of alpha for group comparison purposes were obtained for the questionnaire based on both the 12items $($ alpha $=0.75)$. Participant performance for each item of the LMIC COPD-KQ baseline and 3-months post-education is included in Table 3. When the COPD-KQ was administered at baseline participants scored lowest on items surrounding chronic nature 
of COPD (28.6\%), susceptibility and prevention of pneumonia susceptibility in COPD patients (36.2\%), and the lack of infectious etiology of COPD (41.8\%) (Table 3). At baseline, participants scored highest accuracy on items assessing shortness of breath as a symptom of COPD (94.9\%), burning biomass as a cause and exacerbating factor of COPD (93.9\%), and COPD diagnosis using breathing tests (93.9\%). The questions answered with the lowest accuracy at baseline were items suggesting those with COPD should get a pneumonia vaccine (32.2\%) and that COPD can be reversed (34.6\%). All items improved in performance from baseline to post-education.

\section{COPD Knowledge Questionnaire Performance by Demographic Characteristics}

Women had higher mean baseline and post-education relative to men; however, men had a higher mean improvement in COPDKQ performance relative to women. Both men and women had statistically significant $(p<0.001)$ improvement between baseline and 3months post-education LMIC COPD-KQ scores (Table 4). Participants with a prior COPD diagnosis had a mean baseline score of 8.94 points and mean post-education score of 10.06 points, improving 1.1 points $(95 \% \mathrm{Cl} 0.1$ to 2.2$)$, which was statistically significant $(t=2.3, p=0.040)$. Participants without a prior COPD diagnosis had a mean baseline score of 7.9 points and mean post-education score of 10.2 points, improving 2.3 points ( $95 \% \mathrm{Cl} 1.9$ to 2.7$)$, which was statistically significant $(t=10.7, p<0.001)$. Participants that were smokers and non-smokers independently improved in COPD-KQ performance from baseline to post-education and were statistically significant (Table 4). Participants that had "ever" attended school had the greatest mean LMIC COPD-KQ score improvement among demographic sub-groups (2.6 points, $95 \% \mathrm{Cl} 2.0$ to 3.1 ), and 
this was statistically significance $(p<0.001)$. Never smokers had mean LMIC COPD-KQ improvement of 0.9 point $(\mathrm{t}=2.1, \mathrm{p}=0.038$ ) higher than ever smokers (Table 5). Relative to participants that never attended school, participants that "ever" attended school had 0.9 point $(t=2.2, p=0.026)$ improvement on the LMIC COPD-KQ.

\section{DISCUSSION}

To our knowledge, we have developed and tested the first LMIC-specific COPD Knowledge Questionnaire (LMIC COPD-KQ) and shown that this is locally-adapted, reliable, and responsive to change during a COPD education intervention.

Patient-centered educational interventions have been shown to benefit patients with non-communicable diseases (NCDs) such as COPD. By developing one's sense of selfefficacy, affected individuals build confidence in their ability to actively manage their own condition. ${ }^{7,23,24}$ Hence, providing patient education and improving health literacy is an important aspect of these patient-centered interventions. Currently, there are no COPD knowledge questionnaires specifically tailored to assess COPD health knowledge in LMIC settings, where the COPD burden and mortality is highest. Focus group discussions, an expert panel, and piloting with $\mathrm{CHWs}$ yielded a 12-item questionnaire tested in 196 participants in Nepal, Peru, and Uganda. From baseline test to post-intervention test 3-months later, the educational intervention improved performance and COPD knowledge, on average, by approximately 2.2 points $(95 \% \mathrm{Cl}$ 1.8 to 2.6$)$. 
Our findings are consistent with assessments of COPD knowledge developed in highincome country settings. Maples et al. (2010) developed a 24-item valid and reliable COPD knowledge questionnaire in the United States with similar internal consistency (Cronbach's alpha of 0.72) ${ }^{20}$ Likewise, the Bristol COPD knowledge question (BCKQ), developed in the United Kingdom yielded similar reliability (Cronbach's alpha of 0.73$).{ }^{10}$ Unlike these studies in the US and UK, which consisted of 24 and 65 items respectively, our study involved the development of a 12-item questionnaire for ease of administration and feedback from community members and providers. ${ }^{10,20}$ In contrast to these currently available COPD knowledge questionnaires, our questionnaire focuses on the chronic development of COPD which contrasts the community perception of COPD having an infectious cause in LMIC settings. ${ }^{20}$ In addition to tobacco-smoke exposure, our questionnaire items have a unique focus on biomass exposure as etiological factors and areas of prevention, unlike prior COPD knowledge questionnaires.

COPD-specific education has primarily been delivered in clinical settings in high-income countries. ${ }^{7,25} \mathrm{~A}$ systematic review found that COPD educational interventions were primarily performed in high-income countries in Europe, North America, and Australia with few studies $\left(4.9 \%, 4 / 81\right.$ studies) carried out in LMIC settings. ${ }^{7}$ The majority of COPD education was delivered by healthcare professionals (physicians, nurses, physiotherapists) and few interventions were community-based. However, our CHW-led COPD education was delivered to community members in their homes including topics such as COPD risk factors, symptoms and disease progression, and how to avoid 
exacerbations and maintain general lung health using standardized educational tools. ${ }^{13}$ Due to increased awareness of the burden of chronic respiratory diseases in lowresource settings, COPD-specific education interventions have now expanded in LMIC settings. In Uganda and Vietnam, a train-the-trainer method was implemented for healthcare providers and CHWs to train community members. ${ }^{26}$ This COPD education was found effective in addressing COPD risk factors such as household air pollution and tobacco smoke. Our findings also support van Gemert et al. (2019)'s findings that COPD education can be effectively delivered by local $\mathrm{CHWs}$ to community members outside of clinical settings. ${ }^{26}$

Strikingly, knowledge on COPD substantially improved 3-months post-education in those with and without a prior diagnosis; however, the baseline mean scores between the two groups was only 1.06 points. We would expect that those with a previous diagnosis of COPD would have a better concept and understanding of their disease and score more highly prior to an educational intervention. Knowledge surrounding COPD in LMICs is limited, and our study reiterates the importance of development and assessment of COPD specific knowledge tools as well as the need for identifying those with undiagnosed COPD using quality assured measures and LMIC appropriate casefinding tools.

Question performance differential at baseline was also interesting. We found that participants score higher accuracy on items surrounding shortness of breath as a symptom of COPD (94.9\%), burning biomass as a cause and exacerbating factor of 
COPD (93.9\%), and COPD diagnosis using breathing tests (93.9\%). For a questionnaire aimed at LMICs, knowledge surrounding biomass fuels as a cause and exacerbating factor is paramount when looking at tools to aid COPD preventability. Conversely, the questions answered with the lowest accuracy at baseline were items suggesting those with COPD should get a pneumonia vaccine (32.2\%) and that COPD can be reversed (34.6\%). Limited knowledge surrounding pneumonia vaccines for chronic lung diseases at our study sites was unsurprising given their lack of availability. However, the notion that COPD can be reversed, gives an even stronger case for the need of valid and easily implementable COPD education tools. If it is felt that COPD can be reversed, that misconception lends itself to an even lower incentive (both personal and broader) to minimize and stop exposure and ultimately this will not help prevent new cases of COPD and tackle the current global burden of COPD. While LMIC settings vary in their unique profile of COPD risk factors and healthcare systems, targeting COPD risk factors in prevention, diagnosis, treatment, and management of COPD most prevalent in LMIC settings is key to effective COPD educational interventions and knowledge assessments.

Implementation of CHW-delivered education interventions in community settings has increased in LMICs to prevent and control NCDs. However, there are no studies specifically focusing on COPD, highlighting the need for COPD knowledge tools as COPD education interventions are implemented in LMICs. ${ }^{27}$ COPD knowledge questionnaires can serve as a method for evaluating the educational components of COPD interventions in LMICs. As the burden of COPD increases in LMICs and COPD 
interventions are implemented to address this burden, having an appropriate evaluation tool available is critical.

To our knowledge this is the first COPD knowledge questionnaire developed, tested and found to show face and content validity and with good internal consistency through development phases, suggesting reliability and validity in LMIC settings. A major strength of this study is that we developed content with provider, CHW, and community member input to yield a locally-adapted COPD-KQ specific perspectives and experiences of community members with COPD living in LMICs.

\section{Limitations}

The COPD-KQ content was based on expert panel members' thoughts and biases. To limit this, 16 clinicians, researchers and public health professionals were involved in development. We were not able to conduct focus group discussions in Nepal, and therefore adaptation and cultural contextualization is likely missing. However, we did pilot the COPD-KQ with Nepali CHWs and consulted local physicians to address this limitation. The COPD-KQ was translated into Nepali, Spanish, and Luganda by translators familiar with medical terminology and experienced in translating research, but the questionnaire was not back-translated. In addition, native speakers gave input on questionnaire wording. During fidelity checks by field supervisors in Nepal, it was recognized that a field team was encouraging participants to solicit the 'correct' response. Though refresher training and discussions followed, it is important to highlight this as a potential limitation and risk associated with any questionnaire administration. 
Another limitation is the high frequency of "true" as the correct response (10 of 12 questionnaire items) to the COPD-KQ potentially increasing questionnaire performance for participants that guess "true" for all responses. However, we did a sensitivity analysis to evaluate this and found that less than $0.4 \%$ participants answered "true" for all questionnaire responses. Additionally, the sample size in Peru was relatively small. Given the novelty of the COPD-KQ study, and a lack of alternative questionnaires, concurrent validity could not be assessed. To expand dissemination of this questionnaire to other LMICs, further validation of the COPD-KQ is needed in diverse populations and LMICs with varying interplay of COPD risk factors.

\section{CONCLUSION}

The COPD knowledge questionnaire is a locally-adapted, instrument with acceptable internal consistency that differs in participants with a previous COPD diagnosis. With the development and use of this COPD questionnaire, patient knowledge surrounding COPD and its impact of patient education interventions can be assessed. Healthcare providers and public health professionals alike can utilize the information generated from patient questionnaire responses to enhance patient-centered education efforts based on individual patient needs in clinical settings and evaluate the efficacy of educational interventions. We have developed a questionnaire which, when assessed, shows face and content validity with acceptable internal consistency, suggesting reliability and validity. 


\section{ACKNOWLEDGEMENTS}

We greatly acknowledge the study participants of the GECo study who volunteered their time and made this study possible. We would like to thank Faith Nassali and our research assistants for their involvement in this study. This research was funded by the Medical Research Council Grant MR/P008984/1 under the Global Alliance for Chronic Disease and an Etscorn Summer International Research Award. OFF was supported by NIH Research Training Grant \# D43 TW009340 funded by the NIH Fogarty International Center, NINDS, NIMH, and NHBLI. We declare no competing interests. 


\section{REFERENCES}

1. Islam SM, Purnat TD, Phuong NT, Mwingira U, Schacht K, Froschl G. Noncommunicable diseases (NCDs) in developing countries: a symposium report. Global Health 2014; 10: 81.

2. GOLD. Global Strategy for the Diagnosis, Management, and Prevention of Chronic Obstructive Pulmonary Disease [Internet]. Global Initiative for Chronic Obstructive Lung Disease; 2020 [accessed 2020 Jul 22]. Available from: http://goldcopd.org/.

3. Adeloye D, Chua S, Lee C, Basquill C, Papana A, Theodoratou E et al. Global and regional estimates of COPD prevalence: Systematic review and meta-analysis. J. Glob. Health 2015; 5(2):020415.

4. Yang H, Wang H, Du L, Wang Y, Wang X, Zhang R. Disease knowledge and selfmanagement behavior of COPD patients in China. Medicine 2019; 98(8):e14460.

5. Zwerink M, Brusse-Keizer M, van der Valk PD, Zielhuis GA, Monninkhof EM, van der Palen $\mathrm{J}$ et al. Self-management for patients with chronic obstructive pulmonary disease. Cochrane Database Syst Rev 2014; 3: CD002990.

6. Bourbeau J, Nault D, Dang-Tan T. Self-management and behavior medication in COPD. Patient Educ Couns, 2004; 52(3):271-277. 
7. Stoilkova A, Janssen DJ, Wouters EF. Educational programmes in COPD management interventions: a systematic review. Respir Med 2013; 107(11):1637-50. 8. Wang Y, Zang X, Bai J, Liu S, Zhao Y, Zhang Q. Effect of a Health Belief Modelbased nursing intervention on Chinese patients with moderate to severe chronic obstructive pulmonary disease: A randomised controlled trial. J Clin Nurs 2014; 23(910): $1342-1353$.

9. Wang LH, Zhao Y, Chen LY, Zhang L, Zhang YM. The effect of a nurse-led selfmanagement program on outcomes of patients with chronic obstructive pulmonary disease. Clin Respir J 2020; 14(2):148-157.

10. White R, Walker P, Roberts S, Kalisky S, White P. Bristol COPD Knowledge Questionnaire (BCKQ): testing what we teach patients about COPD. Chron Respir Dis 2006; 3(3): 123-131.

11. Yu S, Guo A, Zhang X. Effects of self-management education on quality of life of patients with chronic obstructive pulmonary disease. Int Journal Nurs Sciences 2014; 1(1): 53-57.

12. Quaderi S, Siddharthan S, Pollard S, Checkley W, Hurst JR, Robertson N. Development and Validation of the Low- and Middle-Income Countries Chronic Obstructive Pulmonary Disease Knowledge Questionnaire (LMIC COPD-KQ) [abstract]. Am J Respir Crit Care Med 2000;161:A466.

13. Siddharthan T, Pollard SL, Quaderi SA, Mirelman AJ, Cárdenas MK, Kirenga B et al.. Effectiveness-implementation of COPD case finding and self-management action plans in low- and middle-income countries: global excellence in COPD outcomes (GECo) study protocol. Trials 2018; 19(1): 571. 
14. Harris PA, Taylor R, Thielke R, Payne J, Gonzalez N, Conde JG. Research electronic data capture (REDCap)—a metadata-driven methodology and workflow process for providing translational research informatics support. J Biomed Inform 2009; $42: 377-81$.

15. Nagourney EM, Robertson NM, Rykiel N, Siddharthan T, Kirenga BJ, Kalyesubula R et al. Illness representations of Chronic Obstructive Pulmonary Disease (COPD) in a rural district of Uganda. Health Educ Res. 2020; 34(4):258-269.

16. Robertson NM, Nagourney EM, Pollard SL, Siddharthan T, Kalyesubula R, Surkan P et al. Urban-Rural Disparities in Chronic Obstructive Pulmonary Disease Management and Access in Uganda. Chronic Obstr Pulm Dis 2019; 6(1):17-28.

17. Ahmad B, Ramadas A, Quek KF. The development and validation of diabetes knowledge questionnaire for the Indigenous population in Malaysia. Med J Malaysia 2010; 65(4): 273-276.

18. Baker HM, Brown RL, Tluczek A. Development and validation of a cystic fibrosis genetic knowledge questionnaire within the general population of the United States. $J$ Cyst Fibros 2013; 12(5): 504-511.

19. Borges MC, Ferraz E, Pontes SM, Cetlin Ade C, Caldeira RD, Silva CS et al. Development and validation of an asthma knowledge questionnaire for use in Brazil. $J$ Bras Pneumol 2010; 36(1): 8-13.

20. Maples P, Franks A, Ray S, Stevens AB, Wallace LS. Development and validation of a low-literacy Chronic Obstructive Pulmonary Disease knowledge Questionnaire (COPD-Q). Patient Educ Couns 2010; 81(1):19-22. 
21. Muijtjens AM, Hoogenboom RJ, Evers JL, vander Vleuten CR. The effects of a "don't know" option on test scores: number-right and formula scoring compared. Med Educ 1999; 33: 267-275.

22. Lavrakas PJ. Encyclopedia of survey research methods. Thousand Oaks, CA: Sage Publications, Inc, 2008.

23. Jolly K, Majothi S, Sitch AJ, Heneghan NR, Riley RD, Moore DJ et al. Selfmanagement of health care behaviors for COPD: a systematic review and metaanalysis. Int J Chron Obstruct Pulmon Dis 2016; 11:305-326.

24. Siddharthan T, Nassali F, Kalyesubula R, Coca S, Rastegar A, Rabin T et al. An educational booklet for patient-centred health education about a non-communicable disease in low-income and middle-income countries. Lancet Glob Health 2016; 4(S25). 25. Blackstock F, Webster K. Disease-specific health education for COPD: A systematic review of changes in health outcomes. Health Education Research 2007; 22(5): 703717.

26. van Gemert F, Brakema E, Van Der Kleij R, Williams S, Jones R, Kirenga B et al. Development and implementation of an awareness programme addressing household air pollution and tobacco smoke: a FRESH AIR project Eur Respir J 2019; 54: (suppl 63) PA728.

27. Jeet G, Thakur JS, Prinja S, Singh M. Community health workers for noncommunicable diseases prevention and control in developing countries: Evidence and implications. PloS one 2017; 12(7): e0180640. 


\section{TABLES}

Table 1. The Chronic Obstructive Pulmonary Disease Knowledge Questionnaire developed by the research team and administered to participants with " $X$ " denoting correct questionnaire responses.

\begin{tabular}{|c|c|c|c|c|}
\hline \multicolumn{2}{|r|}{ Question } & True & False & I don't \\
\hline 1 & $\begin{array}{l}\text { Chronic obstructive pulmonary disease (COPD) is } \\
\text { preventable. }\end{array}$ & $x$ & & \\
\hline 2 & $\begin{array}{l}\text { People with chronic obstructive pulmonary disease (COPD) } \\
\text { often have a cough that won't go away. }\end{array}$ & $x$ & & \\
\hline 3 & $\begin{array}{l}\text { People with chronic obstructive pulmonary disease (COPD) } \\
\text { may feel short of breath. }\end{array}$ & $x$ & & \\
\hline 4 & $\begin{array}{l}\text { Cigarette smoking is a major cause of chronic obstructive } \\
\text { pulmonary disease (COPD). }\end{array}$ & $x$ & & \\
\hline 5 & $\begin{array}{l}\text { Stopping smoking can help to improve symptoms related to } \\
\text { chronic obstructive pulmonary disease (COPD). }\end{array}$ & $x$ & & \\
\hline 6 & $\begin{array}{l}\text { Regular exposure to smoke from burning charcoal, wood, or } \\
\text { dung can cause chronic obstructive pulmonary disease } \\
\text { (COPD). }\end{array}$ & $x$ & & \\
\hline 7 & $\begin{array}{l}\text { Chronic obstructive pulmonary disease (COPD) can be } \\
\text { reversed. }\end{array}$ & & $x$ & \\
\hline 8 & $\begin{array}{l}\text { Chronic obstructive pulmonary disease (COPD) can be } \\
\text { spread from person to person. }\end{array}$ & & $\mathbf{X}$ & \\
\hline 9 & $\begin{array}{l}\text { Chronic obstructive pulmonary disease (COPD) can be } \\
\text { confirmed by breathing tests. }\end{array}$ & $\mathbf{x}$ & & \\
\hline 10 & $\begin{array}{l}\text { People with chronic obstructive pulmonary disease (COPD) } \\
\text { should get a pneumonia vaccination. }\end{array}$ & $X$ & & \\
\hline 11 & $\begin{array}{l}\text { The medicine albuterol (inhaler), Ventolin, or salbutamol } \\
\text { can be used if you feel more short of breath. }\end{array}$ & $x$ & & \\
\hline 12 & $\begin{array}{l}\text { People with chronic obstructive pulmonary disease (COPD) } \\
\text { may be more likely to develop chest infections. }\end{array}$ & $\mathbf{X}$ & & \\
\hline
\end{tabular}


Table 2. Demographic Characteristics of Participants

\begin{tabular}{|c|c|c|c|c|}
\hline $\begin{array}{l}\text { Demographic } \\
\text { Characteristic }\end{array}$ & $\begin{array}{l}\text { Overall } \\
(\mathrm{N}=196)\end{array}$ & $\begin{array}{l}\text { Nepal } \\
(\mathrm{N}=86)\end{array}$ & $\begin{array}{c}\text { Peru } \\
(\mathrm{N}=35)\end{array}$ & $\begin{array}{l}\text { Uganda } \\
(\mathrm{N}=75)\end{array}$ \\
\hline \multicolumn{5}{|l|}{$\operatorname{Sex} n(\%)$} \\
\hline Male & 115 (58.7) & $52(60.5)$ & $19(54.3)$ & $44(58.7)$ \\
\hline Female & $81(41.3)$ & $34(39.5)$ & $16(45.7)$ & $31(41.3)$ \\
\hline Age, years (mean [SD]) & $66.0(11.1)$ & $67.4(9.4)$ & $62.0(11.9)$ & $66.3(12.2)$ \\
\hline $\begin{array}{l}\text { History of ever smoking } \\
\text { tobacco products } n(\%)\end{array}$ & $74(37.8)$ & $28(32.6)$ & $16(45.7)$ & $30(40.0)$ \\
\hline $\begin{array}{l}\text { Currently smoke tobacco } \\
\text { products } \mathrm{n}(\%)\end{array}$ & $32(16.3)$ & $14(16.3)$ & $4(11.4)$ & $14(18.7)$ \\
\hline $\begin{array}{l}\text { Prior COPD diagnosis by a } \\
\text { health professional } n(\%)\end{array}$ & $16(8.2)$ & $16(18.6)$ & $0(0)$ & $0(0)$ \\
\hline Ever Attended School $n(\%)$ & $115(58.7)$ & $23(26.7)$ & $34(97.1)$ & $58(77.3)$ \\
\hline \multicolumn{5}{|l|}{ Highest Educational } \\
\hline None & $81(41.3)$ & $63(73.3)$ & $1(2.9)$ & $17(22.7)$ \\
\hline $\begin{array}{l}\text { Primary school started but } \\
\text { incomplete }\end{array}$ & 62 (31.6) & $11(12.8)$ & $9(25.7)$ & $42(56.0)$ \\
\hline Primary school complete & $29(14.8)$ & $6(7.0)$ & $11(31.4)$ & $12(16.0)$ \\
\hline $\begin{array}{l}\text { Secondary/high school } \\
\text { complete }\end{array}$ & $19(9.7)$ & $3(3.5)$ & $14(40.0)$ & $2(2.7)$ \\
\hline Any higher education & $5(2.6)$ & $3(3.5)$ & $0(0)$ & $2(2.7)$ \\
\hline $\begin{array}{l}\text { Schooling completed, } \\
\text { years (mean [SD]) }\end{array}$ & $3.7(4.2)$ & $1.7(3.8)$ & $7.4(3.7)$ & $4.4(3.5)$ \\
\hline \multicolumn{5}{|l|}{$\begin{array}{l}\text { COPD Knowledge } \\
\text { Questionnaire } \\
\text { Performance }\end{array}$} \\
\hline Baseline (mean [SD]) & $7.97(2.47)$ & $8.92(1.94)$ & $7.03(3.29)$ & $7.32(2.22)$ \\
\hline $\begin{array}{l}\text { Post-Education (mean } \\
\text { [SD]) }\end{array}$ & $10.17(1.67)$ & $10.06(1.81)$ & $9.77(1.63)$ & $10.48(1.48)$ \\
\hline
\end{tabular}


Table 3. LMIC COPD-KQ Item Performance

\begin{tabular}{|l|l|c|c|}
\hline \multicolumn{2}{|l|}{ LMIC COPD Knowledge Questionnaire Item } & \multicolumn{2}{|c|}{ Correct Response n(\%) } \\
\cline { 2 - 4 } & Baseline & Post-Education \\
\hline 1 & $\begin{array}{l}\text { Chronic obstructive pulmonary disease (COPD) is } \\
\text { preventable. }\end{array}$ & $120(61.2)$ & 160 (81.6) \\
\hline 2 & $\begin{array}{l}\text { People with chronic obstructive pulmonary } \\
\text { disease (COPD) often have a cough that won't go } \\
\text { away. }\end{array}$ & $133(67.9)$ & $179(91.3)$ \\
\hline 3 & $\begin{array}{l}\text { People with chronic obstructive pulmonary } \\
\text { disease (COPD) may feel short of breath. }\end{array}$ & $160(81.6)$ & 186 (94.9) \\
\hline 4 & $\begin{array}{l}\text { Cigarette smoking is a major cause of chronic } \\
\text { obstructive pulmonary disease (COPD). }\end{array}$ & $157(80.1)$ & $178(90.8)$ \\
\hline 5 & $\begin{array}{l}\text { Stopping smoking can help to improve symptoms } \\
\text { related to chronic obstructive pulmonary disease } \\
\text { (COPD). }\end{array}$ & $165(84.2)$ & $178(90.2)$ \\
\hline 6 & $\begin{array}{l}\text { Regular exposure to smoke from burning } \\
\text { charcoal, wood, or dung can cause chronic } \\
\text { obstructive pulmonary disease (COPD). }\end{array}$ & $171(87.2)$ & $184(93.9)$ \\
\hline 7 & $\begin{array}{l}\text { Chronic obstructive pulmonary disease (COPD) } \\
\text { can be reversed. }\end{array}$ & $56(28.6)$ & 110 (56.1) \\
\hline 8 & $\begin{array}{l}\text { Chronic obstructive pulmonary disease (COPD) } \\
\text { can be spread from person to person. }\end{array}$ & $82(41.8)$ & $128(65.3)$ \\
\hline 9 & $\begin{array}{l}\text { Chronic obstructive pulmonary disease (COPD) } \\
\text { can be confirmed by breathing tests. }\end{array}$ & $152(77.6)$ & $184(93.9)$ \\
\hline 10 & $\begin{array}{l}\text { People with chronic obstructive pulmonary } \\
\text { disease (COPD) should get a pneumonia } \\
\text { vaccination. }\end{array}$ & $71(36.2)$ & $128(65.3)$ \\
\hline 11 & $\begin{array}{l}\text { The medicine albuterol (inhaler), Ventolin, or } \\
\text { salbutamol can be used if you feel more short of } \\
\text { breath. }\end{array}$ & $139(70.9)$ & $183(93.4)$ \\
\hline 12 & $\begin{array}{l}\text { People with chronic obstructive pulmonary } \\
\text { disease (COPD) may be more likely to develop } \\
\text { chest infections. }\end{array}$ & $156(79.6)$ & 183 (93.4) \\
\hline
\end{tabular}


Table 4. LMIC COPD-KQ performance by demographic characteristics

\begin{tabular}{|c|c|c|c|c|c|}
\hline & \multicolumn{2}{|c|}{$\begin{array}{c}\text { LMIC COPD-KQ Performance } \\
\text { mean (SD) }\end{array}$} & \multirow{2}{*}{$\begin{array}{c}\text { Mean } \\
\text { Difference } \\
(95 \% \mathrm{Cl})\end{array}$} & \multirow{2}{*}{$\begin{array}{c}\text { t- } \\
\text { statistic }\end{array}$} & \multirow{2}{*}{$\begin{array}{c}\mathrm{P} \text { - } \\
\text { value }\end{array}$} \\
\hline & Baseline & Post-Education & & & \\
\hline \multicolumn{6}{|l|}{ Sex } \\
\hline Male & $7.9(2.6)$ & $10.2(1.7)$ & $\begin{array}{c}2.2 \\
(1.7,2.8)\end{array}$ & 7.8 & $<0.001$ \\
\hline Female & $8.0(2.4)$ & $10.2(1.7)$ & $\begin{array}{c}2.2 \\
(1.6,2.7)\end{array}$ & 8.0 & $<0.001$ \\
\hline \multicolumn{6}{|c|}{ Prior COPD diagnosis by a health professional } \\
\hline Yes & $8.9(1.7)$ & $10.1(1.6)$ & $\begin{array}{c}1.1 \\
(0.1,2.2)\end{array}$ & 2.3 & 0.040 \\
\hline No & $7.9(2.5)$ & $10.2(1.7)$ & $\begin{array}{c}2.3 \\
(1.9,2.7)\end{array}$ & 10.7 & $<0.001$ \\
\hline \multicolumn{6}{|l|}{ History of Ever Smoking } \\
\hline Smoker & $8.04(2.5)$ & $9.7(1.8)$ & $\begin{array}{c}1.7 \\
(0.9,2.4)\end{array}$ & 4.5 & $<0.001$ \\
\hline Never Smoker & $7.93(2.5)$ & $10.5(1.5)$ & $\begin{array}{c}2.5 \\
(2.1,3.0)\end{array}$ & 11.0 & $<0.001$ \\
\hline \multicolumn{6}{|l|}{ Current Smoker } \\
\hline Smoker & $8.28(2.6)$ & $9.7(1.9)$ & $\begin{array}{c}1.4 \\
(0.1,2.7)\end{array}$ & 2.2 & 0.039 \\
\hline Non-Smoker & $7.9(2.5)$ & $10.3(1.6)$ & $\begin{array}{c}2.4 \\
(2.0,2.8)\end{array}$ & 11.5 & $<0.001$ \\
\hline \multicolumn{6}{|l|}{ Education } \\
\hline Ever Attended School & $7.7(2.7)$ & $10.2(1.6)$ & $\begin{array}{c}2.6 \\
(2.0,3.1)\end{array}$ & 9.1 & $<0.001$ \\
\hline Never Attended School & $8.4(2.0)$ & $10.1(1.8)$ & $\begin{array}{c}1.7 \\
(1.1,2.2)\end{array}$ & 6.2 & $<0.001$ \\
\hline
\end{tabular}


Table 5. LMIC COPD-KQ change by demographic characteristics

\begin{tabular}{|c|c|c|c|c|}
\hline & $\begin{array}{c}\text { Improvement in } \\
\text { LMIC COPD-KQ } \\
\text { Performance } \\
\text { mean (SD) }\end{array}$ & $\begin{array}{c}\text { Mean } \\
\text { Difference }\end{array}$ & t-statistic & P-value \\
\hline \multicolumn{5}{|l|}{ Sex (Ref: Female) } \\
\hline Female & $2.2(2.5)$ & \multirow[t]{2}{*}{0.1} & \multirow[t]{2}{*}{0.1} & \multirow[t]{2}{*}{0.910} \\
\hline Male & $2.2(3.1)$ & & & \\
\hline \multicolumn{5}{|c|}{ Prior COPD Diagnosis by a Health Professional (Ref: No COPD Diagnosis) } \\
\hline No COPD Diagnosis & $2.3(2.9)$ & \multirow[t]{2}{*}{-1.2} & \multirow[t]{2}{*}{1.6} & \multirow[t]{2}{*}{0.113} \\
\hline COPD Diagnosis & $1.1(2.0)$ & & & \\
\hline \multicolumn{5}{|c|}{ History of Smoking (Ref: Never Smoker) } \\
\hline Never Smoker & $2.5(2.5)$ & \multirow[t]{2}{*}{-0.9} & \multirow[t]{2}{*}{2.1} & \multirow[t]{2}{*}{0.038} \\
\hline Ever Smoker & $1.7(3.2)$ & & & \\
\hline \multicolumn{5}{|c|}{ Current Smoker (Ref: Non-Smoker) } \\
\hline Non-Smoker & $2.4(2.6)$ & \multirow[t]{2}{*}{-1.0} & \multirow[t]{2}{*}{1.5} & \multirow[t]{2}{*}{0.151} \\
\hline Smoker & $1.4(3.6)$ & & & \\
\hline \multicolumn{5}{|c|}{ Education (Ref: Never Attended School) } \\
\hline Never Attended School & $1.7(2.4)$ & \multirow[t]{2}{*}{0.9} & \multirow[t]{2}{*}{2.2} & \multirow[t]{2}{*}{0.026} \\
\hline Ever Attended School & $2.6(3.0)$ & & & \\
\hline
\end{tabular}




\section{FIGURES}

Figure 1. COPD Knowledge Questionnaire Development Methodology Overview

\section{Questionnaire Development and Item Generation}

- Qualitative interviews with healthcare providers, $\mathrm{CHWs}$, and community members with COPD $\rightarrow$ inform item development

\section{Selection of expert reviewers and initial questionnaire development}

- Expert panel: 16 multidisciplinary respiratory clinicians, researchers, and public health professionals worldwide $\rightarrow$ provide expertise, establish domains of questionnaire assessment, and item generation

- Scoping literature review of COPD and NCD knowledge assessments

- Currently published COPD management quidelines

- These steps yielded an initial 52-item COPD knowledge questionnaire

\section{Quality assessment and field testing for comprehension of items}

- Focus group discussions field team members and $\mathrm{CHW}$ leaders

- $\quad$ Pilot questionnaire with a new group of $\mathrm{CHWs}$ collecting performance and written and oral feedback of the questionnaire

- These findings and feedback yielded a final 12-item COPD knowledge questionnaire

\section{Evaluation of changes in knowledge before and after educational} intervention

- Administer COPD knowledge questionnaire at baseline and 3-months posteducation and record performance 